\title{
A significação da avaliação escolar para crianças do quarto ano'
}

\author{
Amanda Nogueira Pereira \\ Sandra Ferraz de Castillo Dourado Freire \\ Universidade de Brasília
}

\section{Resumo}

0 presente estudo objetiva compreender o significado da avaliação para as crianças de quarto ano e as relações que elas estabelecem com o seu processo de aprendizagem. A pesquisa empírica foi realizada com oito crianças que participaram de três encontros de grupo focal e uma entrevista individual. A análise priorizou as interações discursivas e as narrativas de duas participantes. Resultados sugerem que as crianças convivem com várias concepções de avaliação na prática escolar. Embora seja dominante a prática de testes com vistas à nota, elas demonstram um posicionamento crítico acerca da função da avaliação para a própria aprendizagem. Em sua complexidade, a condução da avaliação parece participar significativamente na construção do sentimento delas sobre a experiência escolar.

Palavras-chave: Avaliação escolar. Aprendizagem. Crianças. Anos iniciais.

1. O trabalho empírico foi realizado com o apoio do Programa de Iniciação Cientifica CNPq/ Universidade de Brasília (UnB). 


\section{The significance of school evaluation for fourth grade children}

This paper aims at understanding the imports of school evaluation for fourth-grade children and the relations they establish with their own learning process. Empirical research was conducted with eight children who participated in three focus group meetings, and each gave an individual interview. Results of the analyses of discursive interactions and narratives of two of them suggest that children experience many conceptions of evaluation in school practice. Although the dominant method is applying tests to confer grades, they take a critical stance as to the function of evaluation for learning itself. Complex as it is, the way in which evaluation is conducted seems to participate significantly in the construction of their feeling towards their school experience.

Keywords: School Evaluation. Learning. Children. Elementary education.

\section{La significación de la evaluación para niños de cuarto año primario}

Fue realizado un estudio con niños de cuarto año primario. El objetivo general fue comprender el significado de la evaluación para esos niños y las relaciones que ellos establecen con el proprio aprendizaje. La investigación empírica fue realizada con ocho niños, quienes participaron de tres reuniones de grupo focal y una entrevista individual. Se presenta el análisis de las interacciones discursivas y de las narrativas de dos participantes. Indica que los niños conviven con varias concepciones de evaluación en la práctica escolar cotidiana. Aunque los exámenes sean dominantes, ellos demuestran posicionamientos críticos sobre la función de la evaluación para el proprio aprendizaje. En su complexidad, la conducción de la evaluación parece participar significativamente en la construcción del sentimiento que ellos tienen sobre la experiencia escolar.

Palabras-clave: Evaluación Escolar. Aprendizaje. Niños. Educación primaria. 


\section{Introdução}

0 trabalho apresenta um estudo sobre as perspectivas de crianças do quarto ano do ensino fundamental sobre o processo de avaliação escolar e aprendizagem. 0 objetivo geral consiste em compreender os significados da avaliação escolar para elas e as relações que elas estabelecem entre avaliação e aprendizagem. São objetivos específicos: analisar a narrativa referente aos processos de significação da avaliação escolar, identificar as concepções de aprendizagem, analisar como estabelecem relações entre aprendizagem e avaliação escolar e como elas se veem nesse processo.

A sala de aula é formada por uma complexidade de interações entre professores, alunos e contextos mais amplos em seu processo educativo. Envolve o estabelecimento de múltiplas relações sociais, tanto verticais como horizontais, como professor-aluno, aluno-aluno, relações institucionais, família-escola e escola-comunidade. Diz respeito, também, a relações políticas de ordens diversas, como gestão, infraestrutura e legislação. Enfim, compreender os processos que ocorrem em sala de aula requer um olhar atento aos aspectos das práticas de ensino e aprendizagem em sua multiplicidade, incluindo a compreensão dos sujeitos que participam desses processos.

Considera-se importante priorizar a significação das experiências de aprendizagem vivenciadas pelas crianças ao longo de sua trajetória escolar. Como as práticas pedagógicas, enquanto conjunto de ações que potencializam a aprendizagem e o desenvolvimento, participam do estabelecimento de significados? Estudos mostram que a avaliação escolar, bem como sua condução, demonstram ser uma das instâncias pedagógicas que mais sensibiliza os processos de sala de aula. (Freire, 2008)

Diante dos objetivos propostos para este trabalho, foi priorizado o estudo sobre referências conceituais em avaliação escolar com base nos seguintes autores da área: Ferreira (2009), Freire (2008), Guerra (2007), Hadji (2001), Hoffmann (2011; 2012), Luckesi (2011), Perrenoud (2000), Romão (2011) e Villas Boas (2005; 2007; 2011). Desenvolveu-se, também, pesquisa empírica em uma escola pública de uma região metropolitana brasileira com crianças de quarto ano do Ensino Fundamental.

\section{Aspectos conceituais da avaliação escolar e seus processos}

A avaliação escolar tem desempenhado uma função de destaque nas escolas. É possível observar que existem preocupações, em geral, relacionadas com testes, 
provas, notas, aprovação e repetência, de modo que parece haver uma distância entre avaliação e aprendizagem. A presente seção oferece uma sistematização de abordagens relevantes sobre o tema, apresentando as definições e modalidades de avaliação escolar, destacando a avaliação formativa e a relação entre avaliação, aprendizagem e os processos de ensino e aprendizagem.

A definição de avaliação implica uma variação conceitual relacionada com a diversidade de concepções pedagógicas, finalidades e objetos. Luckesi (2011) apresenta valiosa contribuição ao estudo e compreensão da avaliação. 0 autor diferencia dois processos envolvidos no tratamento dos resultados das aprendizagens dos alunos: a verificação e a avaliação. A verificação da aprendizagem refere-se à prática usualmente utilizada nas escolas de verificar o resultado de maneira quantitativa, apenas visualizando a sua correspondência com padrões definidos, com o propósito de uma classificação dos estudantes; sem a adoção de procedimentos posteriores ao resultado das atividades avaliativas. 0 que o autor denomina de avaliação é exatamente o contrário disso, "o ato de avaliar não se encerra na configuração do valor ou qualidade atribuída ao objeto em questão, exigindo uma tomada de posição favorável ou desfavorável ao objeto da avaliação, com uma consequente decisão" (Luckesi, 2011, p. 52). Assim, a avaliação utiliza os resultados para que sejam formuladas propostas de ações frente ao que foi obtido.

Segundo Luckesi (2011), a verificação está relacionada com a ação de medir. A medida possui um cunho objetivo, uma vez que "significa registrar e atribuir símbolos às dimensões de um fenômeno, a fim de caracterizar-lhe a posição e status" (Romão, 2011, p. 80). Freire (2008) afirma que a utilização simplificada dos desempenhos discentes a partir de instrumentos de medida específicos serve à elaboração de indicadores de qualidade, como prestação de contas da eficácia da ação da instituição educativa especifica, e do próprio sistema educacional, para a sociedade. Entretanto, a ação de medir, tendo em suas bases um padrão e um referencial, acaba por não dar conta da complexidade que envolve a aprendizagem, uma vez que "os fenômenos educacionais não se enquadram em mensurações rígidas". (Romão, 2011, p. 81)

Romão (2011) também sistematiza a avaliação em duas perspectivas. A primeira pode ser compreendida como um "processo de atribuição de símbolos a fenômenos com o objetivo de caracterizar o valor do fenômeno, geralmente com referência a um padrão" (Brandfield; Moredock, 1963 apud Romão, 2011, p. 58); ou, ainda, “avaliar é julgar ou fazer apreciações de alguém ou alguma coisa, tendo como base uma escala de valores" (Hadyt, 1988 apud Romão, 2011, p. 58). A concepção subjacente de educação nessa perspectiva envolve caracterização ou julgamento com referência a um padrão predeterminado. 
A outra perspectiva tem um caráter formativo, uma prática avaliativa direcionada sobre o ensino: "fornecer sobre o processo pedagógico informações que permitam aos agentes escolares decidir sobre as intervenções e redirecionamentos que se fizerem necessários" (Souza, 1993, apud Romão, 2011, p. 59) e "comparação do que foi alcançado com o que se pretendia atingir. Estaremos avaliando quando estivermos examinando o que queremos, o que estamos construindo e o que conseguimos analisando sua validade e eficiência" (Sant'anna, 1995 apud Romão, 2011, p. 59). A avaliação, nesta perspectiva, é concebida como acompanhamento dos processos de ensino e aprendizagem.

Tais perspectivas estão relacionadas com as funções avaliativas praticadas pelas escolas, que podem ser prognóstica, diagnóstica e classificatória (Romão, 2011). A prognóstica possibilita ao professor verificar os conhecimentos e habilidades prévias de seus alunos para que, assim, possa adequar o seu planejamento e práticas com base nas características de sua turma. Essa função é recorrente ao longo do processo de ensino, uma vez que permite ao professor a análise dos conhecimentos de seus alunos necessários para prosseguimento nas etapas seguintes do seu planejamento.

A função diagnóstica prevê a identificação e o acompanhamento das dificuldades dos alunos por meio do desenvolvimento das devidas intervenções. A finalidade dessa função prevalece durante o trabalho do professor, para que ele possa analisar os procedimentos da sua prática e, assim, adequá-los a partir das necessidades dos alunos. 0 erro é um elemento essencial para o professor compreender os processos de aprendizagem de seus alunos e deve ser tratado com cuidado, para que não comprometa a relação entre eles.

A função classificatória objetiva a verificação da assimilação dos conteúdos, desenvolvimento de habilidades e alcance dos objetivos educacionais. Essa função, segundo o autor, é muito utilizada no sistema seriado como forma de "credenciamento do aluno para o enfrentamento da etapa de estudos seguintes". (Romão, 2011, p. 69)

Os conceitos apresentados por Romão (2011) e Luckesi (2011) delineiam elementos constituintes das modalidades de avaliação escolar. A prática avaliativa adquire diferentes finalidades e formatos segundo as concepções e abordagens do professor. A condução das experiências de sala de aula tem relação, em variados níveis de intencionalidade, com a função avaliativa das atividades propostas e a finalidade da avaliação dentro do planejamento pedagógico. Villas Boas (2005) considera que:

a avaliação existe para que se conheça o que o aluno já aprendeu e o que ele ainda não aprendeu, para que se providenciem os meios para que ele aprenda o necessário para 
a continuidade dos estudos [...] não se avalia para atribuir nota, conceito ou menção. Avalia-se para promover a aprendizagem do aluno [...] Aprendizagem e avaliação andam de mãos dadas - a avaliação sempre ajudando a aprendizagem. (Villas Boas, 2005, p. 29)

A autora retoma alguns desses conceitos e funções da avaliação sob a categoria de modalidades de avaliação escolar. Com base na forma com que é utilizada nas práticas escolares, a avaliação pode ser: formal, somativa, classificatória, formativa, informal e diagnóstica. Enquanto as modalidades somativa, classificatória e diagnóstica aparecem contempladas nos trabalhos de Luckesi (2011) e Romão (2011), é interessante, no contexto desta pesquisa, definir as modalidades de avaliação formal, informal e formativa.

A avaliação formal é um conceito amplo que envolve as outras modalidades. Consiste em atividades normalmente previstas no planejamento, elaboradas de acordo com objetivos de ensino e é acompanhada por todos os sujeitos envolvidos no processo avaliativo, isto é, os alunos, professores e pais têm conhecimento da realização dos procedimentos avaliativos e dos seus consequentes resultados. Por outro lado, a avaliação informal é realizada, geralmente, de maneira mais espontânea, estando na base das relações desenvolvidas no espaço escolar. Refere-se às qualificações subjetivas negociadas, explícita ou implicitamente, nas interações entre todos os envolvidos no espaço escolar, dentro ou fora da sala de aula.

A avaliação formativa opõe-se ao modelo convencional de mensuração de resultados e à ideia de avaliação como verificação que tem um fim em si mesmo. Ela pode ser realizada de forma contínua e fazer parte da avaliação formal, informal e da diagnóstica, incluindo atividades avaliativas, como testes e provas. Tem função de analisar as trajetórias de aprendizagem e redirecionar o ensino. Isto é, localiza os aspectos da aprendizagem que possam ser incorporados ao processo de ensino como forma de contribuir à formação de cada aluno em sua singularidade.

Segundo Villas Boas (2011), um dos pioneiros da avaliação formativa foi Benjamin Bloom (1913-1999), que estabeleceu, como objetivo dessa avaliação, a orientação feita aos alunos a respeito do desenvolvimento de seus trabalhos, contribuindo, assim, para a visualização de suas dificuldades e o seu progresso na aprendizagem. A avaliação, nessa perspectiva, tem como finalidade fornecer informações para a reorganização do trabalho pedagógico com vistas às diferenças individuais identificadas, destacando o referido autor que "é necessário que essa reorganização se faça muito antes da atribuição de nota e de se dar prosseguimento às atividades". (Villas Boas, 2011, p. 17)

Outro defensor da avaliação formativa é Philippe Perrenoud (1954-), para quem 
as atividades avaliativas são meios a serviço de finalidades que autorizariam outras trajetórias no ensino. Destaca o cuidado que se deve ter ao utilizá-las para que não fiquem perdidas nas práticas de ensino e que demonstrem sentido e envolvimento para os alunos. Enfatiza a necessidade de o professor estar qualificado para a sua prática e para visualizar o seu aluno de maneira mais completa. A observação, segundo ele, é um importante instrumento de análise, conferindo elementos fundamentais para a atuação do professor. Por meio das observações, o professor pode gerir a progressão das aprendizagens de seus alunos, realizando balanços periódicos que demonstram as aquisições dos educandos e orientam o seu planejamento. (Perrenoud, 2000)

Com relação ao desenvolvimento das atividades da avaliação formativa, Villas Boas (2011) apresenta dois momentos para a sua realização. 0 primeiro referese à percepção dos alunos sobre os objetivos que precisam atingir e, assim, das necessidades para alcançá-los. 0 auxílio de outras pessoas e/ou a autoavaliação são fundamentais para as aprendizagens que deverão ser promovidas para o alcance dos objetivos propostos. 0 segundo momento relaciona-se com as ações desempenhadas para alcançar os objetivos.

A avaliação formativa requer que os alunos estejam diretamente envolvidos no processo. A avaliação da aprendizagem pressupõe uma postura ativa do sujeito no processo de apropriação da atividade escolar como um todo e realiza uma comparação do sujeito com ele mesmo (Freire, 2008). Guerra (2007) corrobora com essa perspectiva ressaltando que, quanto maior a participação dos avaliados, mais potencialidade formativas ela terá e mais reflexiva se tornará a prática.

As implicações da avaliação formativa merecem algumas considerações. Para Hoffmann (2012), a avaliação escolar deve estar articulada com um projeto de ensino, adquirindo sentido quando integrada a uma prática que esteja a serviço da aprendizagem. É uma prática problematizadora, ao contrário “dos instrumentos de avaliação não problematizadores, com questões que induzem à memorização, sem um significado real para a vida dos alunos" (Ferreira, 2009, p. 45). Para Perrenoud (2000), o professor precisa equilibrar-se entre os prazos definidos e as ações necessárias para a promoção do ensino. Ele é desafiado constantemente em face aos conteúdos que devem ser apresentados em tempo hábil para a realização das provas. Inverte-se, assim, o percurso natural, em que a avaliação é promovida para analisar a aprendizagem dos alunos, mas a avaliação se torna uma meta a ser atingida. A superação desse impasse pode estar na condução de práticas que passam a levar em conta a relação experimental do aluno com o conhecimento, uma relação produtiva e significativa com o erro e uma valorização dos acertos e da aprendizagem ocorridas ou em processo.

Enfim, pode parecer que a avaliação formativa caminha na contramão das 
avaliações classificatória e somativa, mas o que faz a diferença é a utilização dos resultados e a reflexão que eles devem promover sobre a aprendizagem. Muitas vezes, o uso de testes e a sua consequente aferição por notas "trabalham com os absolutamente certos e errados, sem perceber qualquer parâmetro intermediário entre tais conceitos" (Hoffmann, 2012, p. 88). Tem-se, assim, a valorização dos acertos das tarefas e a condenação dos erros, seguida, muitas vezes, por recriminações. Quando os erros estão frequentemente envolvidos com a prática de castigos, geram um clima de medo, tensão e ansiedade entre os alunos (Luckesi, 2011). Tais atitudes podem gerar nos alunos uma compreensão culposa da vida, pois, além de serem castigados por outros, também sofrem, muitas vezes, com a autopunição.

Dessa forma, é possível notar que o modo como as notas e os erros são administrados ao longo das atividades escolares e, assim, apresentados para os alunos é um tema delicado que necessita ser promovido com atenção e cuidado, visto que estão em processo de formação do seu autoconceito, podendo gerar atuações danosas sobre essa constituição. Freire (2008) destaca que:

Independente da instância da avaliação, porém, é importante considerar a forma pela qual seus dados e indicadores são construídos, interpretados, registrados, comunicados e divulgados. Pois, no que tange à significação psicológica da avaliação, é no aspecto comunicativo que se processa o significado pessoal que o evento de avaliação repercute nols) sujeito(s) avaliados, no contexto da prática escolar. (Freire, 2008, p. 53.)

É possível reconhecer que existe uma complexidade envolvida nas relações construídas na sala de aula, evidenciando que as ações promovidas nesse espaço incidem sobre o ensino e a aprendizagem. Luckesi (2011) propõe que a avaliação da aprendizagem escolar seja promovida sobre a perspectiva de um ato amoroso, no qual a avaliação fundamenta-se sobre a aprendizagem e é direcionada para uma relação mais próxima e harmônica entre professor e alunos.

\section{Percurso metodológico}

Com base nos objetivos propostos, o trabalho de campo priorizou a metodologia qualitativa com imersão em um "campo natural como sua fonte direta de dados e o pesquisador como seu principal instrumento" (Lüdke \& André, 1986, p. 11). Essa imersão ocorreu em uma sala de aula do quarto ano do ensino fundamental de uma escola pública de uma região metropolitana brasileira. As visitas ocorreram no horário regular da aula para acompanhar a dinâmica da turma, conhecer as 
práticas pedagógicas e estabelecer contato com as crianças, de forma a construir relações de confiança necessárias para a realização dos procedimentos empíricos e o tratamento qualitativo dos resultados.

Visando favorecer a representação subjetiva dos participantes sobre os elementos envolvidos na avaliação escolar e na própria aprendizagem, realizaram-se três encontros de grupo focal e uma entrevista individual com cada participante. Participaram oito crianças de nove a 13 anos, cinco meninas e três meninos, selecionadas mediante convite e demonstração de interesse na pesquisa. Entretanto, para a composição do presente artigo, priorizou-se a análise dos resultados envolvendo dois dos participantes: Samara, de nove anos, e Tadeu ${ }^{2}$ , de 13 anos. Os procedimentos éticos foram observados, contando-se com a assinatura do termo de consentimento livre e esclarecido pelos responsáveis legais, autorizando a participação das crianças na pesquisa.

Foram construídos planos de atividades para a condução dos encontros de grupo focal e roteiro de entrevista para orientar o trabalho de campo e favorecer interações interpessoais e o diálogo. 0 primeiro encontro de grupo focal teve como instrumento motivacional materiais escolares dos anos iniciais de uma das pesquisadoras (P1) - provas, atividades e boletins - que serviram de ponte para conversar sobre os processos envolvidos nas atividades avaliativas vivenciadas pelas crianças em sua sala de aula. 0 segundo encontro foi mediado pelo vídeo "Chico Bento na Escola" (2013), que envolve situações escolares e dilemas, tematizando a relação entre aprendizagem e avaliação. Para o último encontro, foi desenvolvida uma atividade em que as crianças assumiam o papel de professor e criavam uma atividade avaliativa.

A construção do roteiro de entrevista levou em consideração assuntos que emergiram dos encontros de grupo focal e questões que apareceram de maneira particular sobre cada criança. 0 dia da entrevista, realizada no período regular de aula em local reservado, coincidiu com a realização de uma prova de matemática, episódio que oportunizou explorar questões da subjetividade das crianças no momento da entrevista.

Os resultados foram organizados de acordo com a ordem de realização dos procedimentos empíricos em função da dimensão processual que caracterizou o trabalho de campo. Primeiramente apresenta-se a análise das interações discursivas que emergiram dos encontros de grupo focal e, logo, as análises temáticas das entrevistas individuais. Em ambas as análises, foram construídas categorias que foram identificadas com os objetivos específicos e interpretadas à luz das referências conceituais que orientaram teoricamente o estudo.

\footnotetext{
2. Nomes fictícios.
} 


\section{Significações, concepções e relações entre aprendizagem e avaliação: 0 caso de duas crianças}

A sala de aula investigada era formada por 24 alunos. 0 professor regente, formado no curso Normal em nível médio, à época, estava concluindo a sua graduação em pedagogia. Ambos os participantes já haviam repetido de ano pelo menos uma vez e apresentaram atitudes muito diferentes com relação à escola, ao ensino e à avaliação. Durante a pesquisa, Samara demonstrou ser uma menina muito comunicativa, com posicionamentos críticos e sensíveis. Ela tornou evidente, também, o fato de ter muito apreço à leitura, pois seus relatos envolviam seu contato com a biblioteca e com os estudos. Somente na entrevista individual ela revelou que havia reprovado um ano, fato que parecia ocultar de todos. Tadeu, ao contrário, teve uma participação mais tímida nos encontros, evidenciou um sentimento de distanciamento e desconforto com relação à escola, que parecem estar relacionados à defasagem idade-série ocasionada pela entrada tardia na escola e por uma reprovação.

No primeiro encontro de grupo focal, foi possível verificar a relação das crianças com as atividades avaliativas, demonstrando suas concepções e relações com o tema. 0 primeiro conceito que emergiu foi a caracterização de bom e mau aluno, seguido por uma discussão sobre os processos envolvidos na construção e realização da avaliação. Definiram bom aluno como aquele que tem notas altas e demonstra ter aprendido a matéria.

Tadeu não pôde participar desse encontro, pois estava em outra atividade da escola. A seguir, destacam-se as perspectivas apresentadas por Samara. Esta aluna foi além da ideia de bom aluno como aquele que tira notas altas ao dizer que "ser um bom aluno é tentar melhorar; (...) se você errou alguma coisa, você pode tentar melhorar no que você errou". Demonstrou uma noção mais consciente sobre a aprendizagem como processo e sobre a atitude de um aluno, a quem atribui o desejo de melhora sobre as dificuldades encontradas anteriormente.

Para Samara, prova é sinônimo de "dificuldade (...) tudo o que a gente estudou em um ano vai dar a prova. Você tem que revisar tudo pra fazer a prova”. Esta perspectiva está envolvida com a função classificatória apresentada por Romão (2011), de modo que o seu objetivo estaria relacionado com uma simplificada verificação da assimilação das crianças sobre o conteúdo. É um procedimento desvinculado da prática do ensino e do cotidiano de sala de aula, que exige das crianças uma preocupação com o acúmulo da matéria. Ocorre uma inversão da relação entre avaliação e aprendizagem, em que o conteúdo está a serviço da avaliação e não o contrário. 0 comentário da menina sobre a dificuldade pode confirmar esse pensamento, desvinculando a prova das atividades de aprendizagem cotidianas da sala de aula.

O diálogo foi caracterizado por comentários que demonstravam nervosismo 
na realização das avaliações, como "ter um branco" na resolução de questões que consideraram ter maior dificuldade. Samara justifica: "porque toda aquela matéria foi difícil para a gente pegar". Nesse caso, deve-se fazer uma reflexão sobre os processos relacionais envolvidos na experiência da criança com a atividade avaliativa. De alguma forma, a insegurança sinalizada por Samara pode sugerir a falta de apoio ou sentimento de incapacidade na realização da atividade gerada na avaliação informal. 0 "branco" pode estar sugerindo a existência de uma pressão pelo acerto, gerando um clima de medo, tensão e ansiedade, provocando disposição desfavorável para a realização da atividade avaliativa (Luckesi, 2011). Ao mesmo tempo, a explicação de Samara indica que o conhecimento, como objeto e objetivo da aprendizagem, é algo externo, não faz parte da subjetividade dela como aluna.

0 segundo encontro de grupo focal iniciou com o vídeo "Chico Bento na Escola". 0 vídeo mostra uma situação em que a professora apresenta um problema matemático para o Chico Bento e ele passa o dia todo perguntando aos colegas qual seria a resposta certa. Os colegas não o ajudam e vão propondo outras reflexões sobre o problema matemático apresentado pela professora, de forma que a questão vai ficando cada vez mais complexa, até que a personagem Rosinha, em meio a uma discussão, dá a resposta sem querer. No dia seguinte, Chico Bento apresenta para a professora a resposta ao problema (dada por Rosinha) e fica orgulhoso de ter acertado. A professora, porém, passa um novo problema, e o personagem acaba caindo no chão em desapontamento.

As crianças acompanharam atentamente a exibição do vídeo e, com a sua finalização, foi possível desenvolver uma discussão que envolveu vários tópicos, entre eles: aprendizagem, cola, professor e a relação dos pais com as notas.

Inicialmente, o diálogo desencadeou uma reflexão sobre a aprendizagem de Chico Bento. Para as crianças, ele não aprendeu, pois ele saiu perguntando para os colegas e recebeu a resposta pronta da Rosinha. Dessa forma, para as crianças, ele não resolveu a operação, porque não desenvolveu o seu pensamento. Segundo elas, 0 ato de pensar caracteriza a aprendizagem.

Entretanto, foi demonstrada a existência de práticas ambivalentes acerca da aprendizagem e da socialização do conhecimento. Se, por um lado, elas compreendem que a aprendizagem envolve pensar, no cotidiano da sala de aula, há também situações em que as crianças interagem somente em função da resposta certa, ao buscar com os colegas apenas a resposta do exercício. Tadeu disse: "eu vou no Jorge $^{3}$ (....) e pergunto quanto é tal, tal, aí ele faz a conta e me passa a questão [a resposta]". Isso demonstra que a ênfase é apenas na conclusão da tarefa, na resposta certa, sem a preocupação com o desenvolvimento do

3. Nome fictício. 
conhecimento ou aprendizagem, não envolvendo o ato de pensar sobre a questão para compreendê-la.

Ao mesmo tempo, segundo as crianças, os colegas contribuem para a aprendizagem, não no sentido de dar a resposta certa, mas quando ajudam a compreender a questão, conforme pode ser destacado nos comentários da Samara:

Pesquisadora 1: E na hora de fazer o dever, para quem vocês pedem ajuda?

Samara: Às vezes eu peço ajuda para o professor (...) Tem vezes que eu pergunto para a Carolina ${ }^{4}$ e ela me ajuda, aí, eu consigo fazer a conta.

Pesquisadora 1: Vocês acham que desse jeito vocês estão aprendendo?

Samara: Só ajudando, fazendo não. Fazendo [para o outro] a gente não aprende, mas ajudando sim.

Pesquisadora 1: Quando ajuda o outro, você acha que aprende?

Samara: Aprende.

A narrativa da Samara sinaliza o valor da socialização. É por meio da relação promovida nas ações de colaboração que ocorre a aprendizagem. Ela demonstra acreditar que é mediante a ajuda mútua que se efetiva a aprendizagem.

Com relação ao tema da cola, as crianças fizeram referência à atitude da personagem Rosinha ao falar a resposta do problema matemático para Chico Bento, qualificando-a como algo feio. No entanto, a conversa teve outra abordagem, quando a discussão foi recontextualizada na rotina da própria sala de aula. Elas relataram fazer uso de cola em avaliações e visualizaram isso como um fato positivo, uma vez que conseguem acertar a questão. No decorrer da conversa, elas reconheceram que o mais importante seria aprender, o que não iria ocorrer com a prática da cola.

Samara: Tinha dia que a gente passava papelzinho para cada uma.

Pesquisadora 1: Mas o que vocês acham disso, de pegar e passar cola?

Samara: Feio.

Pesquisadora 1: E você Tadeu?

Tadeu: Eu pegava o caderno.

Pesquisadora 1: E o que você acha disso?

Tadeu: Bonito... Porque eu acertava mesmo.

Pesquisadora 1: Acertar desse jeito... Vocês acham que vale a pena?

Crianças: Vale.

4. Nome fictício. 
Samara: Aí, no outro ano a gente não vai saber.

Pesquisadora 1: Pois é, vocês podem acertar a questão... Mas vocês vão ter aprendido? Crianças: Não.

Pesquisadora 1: 0 que é mais importante, acertar ou aprender?

Crianças: Aprender.

Apesar de reconhecerem que o importante é aprender, nota-se que o marcante nesse diálogo foi a perspectiva demonstrada pelas crianças com um maior destaque pelo acerto da questão e não propriamente com a aprendizagem. Segundo Luckesi (2011), a escola se fundamenta pelo ato de examinar e, com isso, classificar o aluno entre aprovado e reprovado. 0 autor enfatiza que há uma preocupação com o tirar nota e não com o aprender. Hoffmann (2011) também confirma essa posição, de que existe, na escola, uma preocupação com os acertos, de modo que os erros são desqualificados. Dessa forma, o que foi demonstrado pelas crianças se torna consequência das características da concepção examinadora de educação praticada. Nesse sentido, elas acabam se importando apenas com o acerto da questão, de forma que "os fins justificam os meios".

Ao conversar sobre a professora do Chico Bento, as crianças também falaram sobre as práticas do professor regente da turma. Esse pareceu ser um momento de desabafo para as meninas do grupo. Elas se mostraram incomodadas com os julgamentos do professor quando ele enfatiza a dificuldade delas para a resolução das atividades e quando sugere problemas para que elas passem de ano. 0 professor também promove comparações entre os colegas da turma e isso parece gerar sentimentos de indignação entre elas.

As situações apresentadas pelas crianças evidenciam a sensibilidade envolvida na avaliação informal. Foi possível perceber que a relação com o professor é afetada pelos comentários dele, gerando uma instabilidade emocional a partir do que o professor pensa delas. Isso ilustra o quão importante é estabelecer uma relação entre professor e alunos baseada no respeito mútuo. 0 professor precisa desenvolver o seu trabalho de maneira que desperte a confiança e o interesse nas crianças para a aprendizagem. Para tanto, é preciso que seus comentários sejam encorajadores e que as dificuldades e especificidades sejam respeitadas e preservadas em momentos particulares, sem a exposição na frente da turma ou a promoção de comparações.

Com relação aos resultados das provas, foi discutido sobre os sentimentos das crianças a respeito do que seus pais pensam sobre elas diante das notas. Disseram que se sentem felizes com notas altas e tristes com notas baixas, pois, quando tiram notas altas, os pais ficam orgulhosos delas e alguns dão recompensas, como presentes e viagens. Tadeu foi provocativo ao dizer que não é a nota que the 
causa felicidade, mas a recompensa. Disse que, quando tirou dez em uma prova, não sentiu "nada... Eu só senti cinquenta reais na minha mão". A relação entre a nota e a atitude dos pais é complexa no sentido de gerar interações e significados, articulando um sistema de recompensa à demonstração de afeto. Dessa forma, a supervalorização das notas esconde o significado que tem a aprendizagem, como no caso do Tadeu, que demonstrou que só valoriza a nota pelo benefício pessoal que ela gera, sem uma preocupação com a aprendizagem.

0 último encontro retomou as discussões anteriores com enfoque sobre as perspectivas das crianças sobre a relação aprendizagem e avaliação, ao assumirem o papel de professores. Primeiramente, conversaram sobre formatos de avaliação alternativos à realização de provas e exames. Em geral, as propostas ficaram na estrutura tradicional, mudando provas por trabalhos feitos em sala que valeriam nota. Samara foi a única que inovou, destacou que a avaliação teria que ser diferente, "não o professor passando" uma prova. Talvez isso indique uma concepção de fluidez sobre a relação entre aprendizagem e avaliação. Sua posição apresenta aspectos relativos à avaliação formativa e à posição de avaliação defendida por Luckesi (2011). A avaliação se daria mediante atividades que orientassem os alunos no desenvolvimento de suas aprendizagens ao longo do processo de ensino e não somente em momento terminal. Entretanto, Samara não se desvinculou da nota, sendo essa resultado da somatória das atividades propostas por ela. A perspectiva da nota aparece como uma exigência social enraizada sob as práticas educativas. Muitas vezes, os próprios alunos admitem a necessidade de notas para aferição de seu rendimento.

Em um segundo momento, as crianças falaram sobre suas próprias habilidades e foi proposto que elas teriam que escolher aquilo que faziam melhor para ensinar aos outros. No papel de professor, elas deveriam realizar uma atividade avaliativa para os seus alunos. As questões motivadoras foram: "Como vocês vão saber que os seus alunos estão aprendendo? E como eles vão saber que estão aprendendo e melhorando naquela habilidade?".

Tadeu desenvolveu uma atividade sobre como jogar videogame. Desenhou uma prova em que, por meio da demonstração dos alunos jogando, seria possível perceber se eles teriam aprendido. A habilidade destacada por Samara foi a culinária. A avaliação consistiu no preparo de um bolinho de carne. Segundo ela, a verificação da aprendizagem seria promovida pela prova do prato.

Por fim, foram abordadas algumas questões envolvidas na elaboração das provas e nos resultados dessas. A pesquisadora 1 perguntou para as crianças sobre o que acharam de criar uma atividade avaliativa, e elas afirmaram que tinham gostado da atividade, mas também demonstraram ter encontrado dificuldades. Para Samara, “a gente vai ter que ver o que eles já estão tentando fazer, e o que 
não. Quando a gente for passar [uma avaliação], a gente coloca questões fáceis e difíceis. Porque aí tem gente que fala que só tem questão difícil, mas não é. É que você não prestou atenção na aula". Isso demonstra que sua noção sobre o processo de aprendizagem relaciona duas abordagens para a aquisição de conhecimentos: questões fáceis e difíceis. Fácil é o que o aluno já está tentando fazer e difícil é aquilo que ele não faz. Para ela, essas abordagens poderão demonstrar a posição do aluno no processo de aprendizagem. É possível notar, também, que ela desenvolveu um posicionamento como professora, aproximando-se de uma postura como tal e preocupando-se com a sua atuação com os seus alunos. A relação entre as questões fáceis e difíceis perpetuou-se ao longo da conversa, destacando a concepção das crianças de que a aprendizagem ocorre em função dos comportamentos em sala de aula.

Por fim, eles falaram sobre os tipos de alunos que queriam ter, apresentando as características: ótimos, bons, espertos e obedientes. Novamente, o comentário de Samara merece destaque: "eu queria que eles se sentissem assim... Quando eles entrassem na sala, eles soubessem que eles também teriam muitas dificuldades, mas também vão ter muitas coisas boas na sala... Que pode brincar na sala, mas tem o tempo de brincar, tem a hora de aprender e tem a hora, tipo na minha aula, tem a hora da gente fazer a comida, e pra escrever tudo o que aprendeu". Ela demonstra, assim, o conhecimento de que a escola é formada por uma complexidade de relações e interações, em que o processo de ensino e aprendizagem está envolvido com responsabilidades e comprometimento. Contudo, a escola também oferece oportunidades de diversão.

$\mathrm{Na}$ realização das entrevistas individuais, a análise da narrativa das crianças priorizou seus posicionamentos acerca do conceito de aprendizagem e sobre as atividades avaliativas realizadas na escola.

A concepção de Samara sobre a aprendizagem apareceu relacionada com a prática da leitura. Ela explicou como é o seu processo para aprender: "ler o que eu fiz, ler, reler, até eu entender" e "indo na biblioteca". Disse que as pessoas que podem auxiliá-la no processo de aprendizagem eram "todas aquelas que eu fico perto", mencionando os seus familiares. A ajuda dos outros, para ela, pode ser interpretada como uma ação formativa: "eu faço uma coisa, eles veem que está errado ou não... Aí eles vão lá e me explicam o jeito que é certo. Mas não é porque eu errei, é porque eu não peguei ainda a matéria". 0 erro aparece, assim, como propulsor para a aprendizagem e o desenvolvimento. Entretanto, é possível observar que a aquisição do conhecimento relaciona-se com a ideia de "pegar" como se fosse externo a ela. Os seus comentários revelam uma preocupação com as avaliações, conforme Hoffmann (2011), envolvidos com a crítica que se faz sobre os erros e a preocupação com os acertos, que são amplamente valorizados, 
e se tornam reféns de julgamentos de outros considerados superiores.

Ao falar das atividades avaliativas, o tema revelou uma novidade que ainda não tinha sido apresentada por ela nos encontros anteriores: a reprovação. Ela demonstrou medo para a realização de provas, temendo uma nova reprovação e o que isso poderá representar para a sua mãe, uma vez que, "se eu reprovar mais uma vez, minha mãe não vai falar comigo, vai me deixar de castigo por um bom tempo". Luckesi (2011) explica que a promoção de castigos sobre os erros gera um clima de medo, tensão e ansiedade nos alunos. Situações envolvidas com o erro podem acarretar nos alunos uma compreensão culposa da vida, e eles sofrem, muitas vezes, com a autopunição. Essa configuração de concepção educativa não possibilita um ambiente saudável para o desenvolvimento do processo de ensino e aprendizagem, pois os alunos acabam envolvidos por sentimentos de preocupação e angústia sobre os resultados, uma vez que esses podem gerar consequências diversas.

Contudo, apesar dos sentimentos demonstrados, Samara possui uma perspectiva positiva sobre os acontecimentos, acreditando que a sua reprovação foi justa, uma vez que "eu não tinha aprendido, porque, se eu fosse pra outra série, eu também não ia saber nada daquilo, por causa daquela série... porque o conteúdo da outra série ia ser o mesmo da outra, só que mais difícil".

Diferentemente de Samara, Tadeu explica sua aprendizagem pela ação do professor. Para ele, é o professor quem decide se vai passar de ano e se ele aprendeu. Demonstra que a aprendizagem escolar é externa e o trabalho escolar parece carecer de sentido. Sente-se inseguro sobre a própria aprendizagem e, como sinalizam Hoffmann (2011) e Perrenoud (2001), isso faz com que se sinta refém das decisões, para ele arbitrárias, do adulto.

Por outro lado, parece ter uma noção mais ampla de aprendizagem fora da escola: "a gente aprende com tudo, até em casa a gente aprende". Menciona valores, como "aprende a ter responsabilidade com as suas coisas, educação". Considera que aprende mais em casa do que na escola, pois "em casa, até na rua ... eu aprendo a respeitar os outros, falar com os meus amigos". Nesse sentido, ele parece fazer uma dicotomia entre aprender em casa e aprender na escola. Para ele, são dois mundos distintos, em que a aprendizagem na escola é totalmente vinculada ao professor e desconexa com a vida cotidiana dele.

Com relação às atividades avaliativas, perceberam-se duas questões importantes: uma referente à realização das provas e outra referente à relação dos pais com os resultados. Ele relata sentir "medo de errar" e apreensão sobre como o professor irá reagir e também se refere de forma significativa ao pai; quando tira uma nota ruim, "fico de boa... Só falo pro meu pai que eu tirei uma nota ruim, aí ele fala 'tá bom”, aí tipo... se for um mês de festa, Natal... meu aniversário, 
aí tipo, ele fala que 'ao invés de ganhar isso, você vai ganhar isso'”. Há sempre uma recompensa do pai: uma nota maior requer um presente mais caro e uma nota menor, um presente mais barato.

Essa relação é refletida sobre a preocupação do Tadeu com o seu rendimento nas avaliações, acreditando que “tenho que tirar só nota boa, só para eu ganhar presente". No entanto, quando questionado sobre uma preocupação exclusiva com as recompensas que os resultados nas provas poderiam the proporcionar, ele relacionou a importância da escola com um futuro longínquo.

Os procedimentos empíricos possibilitaram visualizar a compreensão das crianças sobre a complexa relação entre a aprendizagem e a avaliação escolar. Notou-se que há, nessa relação, um envolvimento muito próximo com as notas, os sentidos da aprovação e sentimentos que se relacionam com os resultados. Entretanto, é uma série de contradições e paradoxos na prática educativa que aparece nas interações discursivas e narrativas das crianças. Os resultados mostram como as crianças são agentes ativos nesse processo de canalização cultural pela escola e que há possibilidades de uma diversidade de significações.

\section{Considerações finais}

0 trabalho de campo permitiu conhecer mais sobre a rotina da turma do quarto ano e, assim, contemplar, ainda que provisoriamente, o objetivo proposto no sentido de compreender as complexas relações que se estabelecem nos processos de ensino e aprendizagem a partir das perspectivas de duas crianças. Alguns diálogos, ao longo dos encontros de grupo focal, possibilitaram perceber que o trabalho avaliativo é entendido dominantemente sob a abordagem verificacionista de Luckesi (2011), como demonstra a fala de Samara, quando define a prova como "dificuldade; (...) tudo o que a gente estudou em um ano vai dar a prova. Você tem que revisar tudo pra fazer a prova”. Isso se relaciona com a prática de avaliações formais de função classificatória. Em parte, as crianças apresentaram uma compreensão sobre avaliação escolar relacionada a tais concepções.

No entanto, elas também fizeram referências a outras modalidades de avaliação escolar, como a avaliação informal e a avaliação formativa, destacando a importância dessas em relação à aprendizagem. Parece haver uma ideia de que a aprendizagem para a prova é diferente da aprendizagem para a vida e que a última envolve uma relação compreensiva com o objeto de aprendizagem, acarreta mudanças pessoais e desenvolvimento de valores, como demonstrado por Tadeu: "em casa, até na rua ... eu aprendo a respeitar os outros, falar com os meus amigos". 
É interessante destacar que, mesmo estando no início da escolarização, as crianças demonstraram ter uma compreensão já consolidada sobre avaliação como verificação e da sua função classificatória. Parece haver um significado dominante para as crianças: de que a avaliação serve para aprovar ou reprovar. Nessa concepção, a aprendizagem escolar está a serviço da prova e da nota, ao contrário do que defende a concepção formativa em que as atividades avaliativas devem estar a serviço da aprendizagem.

Foi possível identificar que existe uma relação importante entre a avaliação informal e as concepções que eles estão construindo de si mesmos como alunos. Há uma compreensão de que o bom aluno é quem tira nota alta e tem bom comportamento na sala de aula. De forma unânime, os participantes disseram que nota alta gera felicidade e nota baixa, tristeza. Essa forma de compreender o ser aluno apenas pela nota que tira é muito limitada, porque reflete na relação da criança com a aprendizagem, o que pode corroborar para o distanciamento entre a escola e as outras experiências para além da escola.

Deve-se entender, também, que esse é um processo dinâmico e que é possível construir outros significados. Nos procedimentos empíricos, especialmente no grupo focal, as crianças fizeram referência ao aprender como noção de compreensão do objeto de estudo e ao ato de pensar. Relacionaram a importância do professor, dos familiares e dos colegas orientando a realização da tarefa; o papel da concentração e da atenção nas aulas no momento da explicação e apresentação da matéria e da correção do exercício. Mostraram compreender a aprendizagem como processo que se dá ao longo da escolarização, dizendo que a passagem das séries oportuniza mais conhecimentos e a dificuldade dos conteúdos aumenta.

0 erro foi um elemento de destaque nas discussões. As crianças mencionaram recorrentemente que, quando erram, também aprendem e podem superar as dificuldades. 0 olhar positivo sobre o erro confirma a ideia de Luckesi sobre tomá-lo como ponto de partida para a aprendizagem. Uma vez identificados e compreendidos, tem-se a possibilidade da superação. Dessa forma, a avaliação é assumida segundo a sua fundamentação original, a investigação da aprendizagem e o erro, como destacado pela avaliação formativa, se torna um elemento essencial para orientar o trabalho do professor e dos alunos.

\section{Referências}

FERREIRA, Lucinete Maria Souza. Retratos da avaliação: conflitos, desvirtuamentos e caminhos para a superação. Porto Alegre: Mediação, 2009.

FREIRE, Sandra Ferraz de Castillo Dourado. Concepções dinâmicas de si de crianças 
em escolarização: uma perspectiva dialógico-desenvolvimental. 2008. xvi, 264 p.: Tese (doutorado) - Universidade de Brasília, Instituto de Psicologia, Programa de Processos de Desenvolvimento Humano e Saúde, 2008.

GUERRA, Miguel Ángel Santos. Uma flexa no alvo: a avaliação como aprendizagem. ed. São Paulo: Loyola, 2007.

HADJI, Charles. Avaliação desmistificada. Porto Alegre: Artmed, 2001.

HOFFMANN, Jussara. Avaliação mediadora: uma prática em construção da préescola à universidade. 32. ed. Porto Alegre: Mediação, 2012.

HOFFMANN, Jussara. Avaliação: mito e desafio: uma perspectiva: uma perspectiva construtivista. 42. ed. Porto Alegre: Mediação, 2012.

LÜDKE, Menga \& ANDRÉ, Marli E.D.A. Pesquisa em educação: abordagens qualitativas. Disponível em: <rbep.inep.gov.br>. Acesso em: 20 ago. 2013.

LUCKESI, Cipriano Carlos. Avaliação da aprendizagem escolar: estudos e proposições. 22. ed. São Paulo: Cortez, 2011.

RICHARDSON, Roberto; WAINWARIGHT, David. A pesquisa Qualitativa crítica é válida. In: RICHARDSON, Roberto (Org). Pesquisa Social. 3. ed. São Paulo: Ed. Atlas. ROMÃO, José Eustáquio. Avaliação dialógica: desafios e perspectivas. 9. ed. São Paulo: Cortez, 2011.

VILLAS BOAS, Benigna Maria de Freitas. Portfólio, avaliação e trabalho pedagógico. 2. ed. Campinas: Papirus, 2005.

. (Org.). Avaliação formativa: Práticas inovadoras. Campinas, SP: Papirus, 2011. . Pedagogia: A avaliação na escola. Brasília: Universidade de Brasília, 2007. pp. 10-23. Disponível em:< http://www.fe.unb.br >. Acesso em: 15 set. 2013.

YOUTUBE. Chico Bento na escola. Disponível em: <www.youtube.com >. Acesso em: 20 ago. 2013.

Recebido em junho de 2014

Aprovado em dezembro de 2014

Amanda Nogueira Pereira é graduada em pedagogia pela Universidade de Brasília (UnB). É pesquisadora da área escolar em séries iniciais com participação no Programa de Iniciação Científica (ProlC-UnB). E-mail: amanda.anplahotmal.com

Sandra Ferraz de Castillo Dourado Freire é doutora em psicologia pelo Programa Processos de Desenvolvimento Humano e Saúde da Universidade de Brasília (UnB), professora da área de Psicologia da Educação da Faculdade de Educação da UnB. E-mail: sandra.ferraz@ggmail.com 